\title{
Fungos aquáticos (Oomycota, Chytridiomycota) ocorrentes em anfíbios anuros em dois remanescentes de Mata Mtlântica, localizados em Santa Cruz do Sul e Venâncio Aires, RS, Brasil
}

\author{
Aquatic fungi (Oomycota, Chytridiomycota) ocurring in anuran amphibians in two remaining of \\ the Atlantic Forest in Santa Cruz do Sul and Venâncio Aires municipalilties, Southern Brazil
}

\section{Francine Kist Closs}

Universidade de Santa Cruz do Sul - Unisc - Santa Cruz do Sul - Rio Grande do Sul - Brasil

\section{Jair Putzke}

Universidade Federal do Pampa - Unipampa - Bagé - Rio Grande do Sul - Brasil

\section{Resumo}

Fungos patógenos de anfíbios estão entre os maiores vilões à biodiversidade de anuros, sendo de extrema importância um maior conhecimento destes organismos causadores de doenças. Buscou-se conhecer os fungos zoospóricos ocorrentes em anuros em remanescentes de Mata Atlântica na região de Venâncio Aires e Santa Cruz do Sul - RS. As amostragens em campo realizaram-se entre outubro de 2014 e abril de 2015, em Linha Estrela em Venâncio Aires e dentro da UNISC em Santa Cruz do Sul. As amostragens de anuros foram feitas a partir do método de procura visual ativa e procura em sítios de reprodução. Em laboratório, foi utilizado o método de isolamento por iscas para fungos aquáticos, adaptada. Foram amostrados 24 indivíduos de Anura, compostos por 9 espécies, enquadrados em 3 famílias (Hylidae, Leptodactylidae e Leiuperidae). Destes, 21 indivíduos apresentaram fungos zoospóricos, onde observou-se a ocorrência dos gêneros Achlya, Saprolegnia, Leptomitus, Apodachlya, a espécie Batrachochytrium dendrobatidis e indivíduos não identificados do filo Chytridiomycota. Até então, a ocorrência de $B$. dendrobatidis na região de estudo ainda não havia sido registrada, sendo este um dado alarmante.

\section{Abstract}

Amphibian fungal pathogens are among the greatest villains to the biodiversity of this group in the world, being of extreme importance a greater knowledge of these disease causing organisms. We sought to know the zoosporic fungi that occur in amphibians in Atlantic Forest remnants in the region of Venâncio Aires and Santa Cruz do Sul municipalities in Rio Grande do Sul State, southern Brazil. Sampling in the field took place from October 2014 to April 2015, in Linha Estrela, countryside of the city of Venâncio Aires, and within the University of Santa Cruz do Sul campus, in Santa Cruz do Sul. The anuran samplings were made using the active visual search method and looking at breeding sites. In the laboratory, the method of isolation by baits for aquatic fungi (adapted) was used. We sampled 24 individuals of Anura, consisting of 9 species, classified in 3 families (Hylidae, Leptodactylidae and Leiuperidae). From these, 21 individuals presented zoosporic fungi, in which we observed the occurrence of Achlya sp., Saprolegnia sp., Leptomitus sp., Apodachlya sp., the species Batrachochytrium dendrobatidis and individuals not identified of the Chytridiomycota phylum. Until then, the occurrence of $B$. dendrobatidis had not been registered, which is an alarming fact.

\section{Palavras-chave}

Fungos Zoospóricos. Patógenos. Mata Atlântica. Anurofauna.

\section{Keywords}

Zoosporic fungi. Pathogens. Atlantic Forest. Anuran fauna. 


\section{Introdução}

O Brasil é o país com a maior riqueza de espécies de anfíbios no mundo, contendo 1.080 espécies de anfíbios anuros (SOCIEDADE BRASILEIRA DE HERPETOLOGIA, 2016).

Os anfíbios são sensíveis às alterações ambientais porque possuem a pele permeável e um ciclo de vida bifásico, com a maioria das espécies dependendo da água para realizar a reprodução. As atividades antrópicas sobre o meio ambiente tem colaborado muito em aspectos negativos para as populações de anfíbios. Um dos maiores problemas são a perda de habitat, introdução de espécies invasoras, aumento da incidência de radiação ultravioleta, poluição e doenças (VERDADE et al. 2010). As consequências destas alterações ambientais podem ser sentidas pelos anfíbios de diversas formas, como alterações na metamorfose e no comportamento, maior susceptibilidade a infecções e mudanças nas áreas de distribuição, devido as mudanças extremas de temperatura (COSTA et al. 2012).

De acordo com Assis (2012), a microbiota da pele dos anfíbios, aliada a mecanismos bioquímicos e biológicos, derivados da secreção das glândulas epidérmicas dos mesmos, lhes confere uma proteção natural contra microrganismos, porém, esta proteção pode ser afetada quando estes animais estão expostos às condições ambientais desfavoráveis, podendo aumentar a susceptibilidade a agentes patogênicos.

A maioria das espécies de anfíbios são carnívoras e se alimentam de insetos, porém sua dieta pode variar bastante, incluindo também aracnídeos, anelídeos, moluscos, crustáceos e até outros anfíbios (SANTOS et al. 2004). Estes animais desempenham um importante papel na cadeia alimentar, controlando diversas populações de insetos e outros invertebrados. (COLOMBO e ZANK, 2008). Além disso, muitas espécies são consideradas bioindicadoras do ambiente, de modo que sua ausência ou presença em determinado local pode indicar alterações ecológicas (BORGES-MARTINS et al. 2007).

Para entender melhor este assunto, devemos relacionar essas espécies com os possíveis microrganismos e parasitas que os mesmos carregam, como fungos epidérmicos. Descobertas anteriores revelaram que fungos patógenos vêm sendo um dos causadores do declínio nas populações de anfíbios, incluindo no bioma Mata Atlântica (VALENCIA-AGUILAR et al. 2015).

A região de estudo ainda não apresentou nenhum trabalho sobre fungos relacionados com anfíbios, sendo este inédito para a região e, tendo em vista a conservação e correto manejo da biodiversidade, conhecer os possíveis fungos ocorrentes nos animais em estudo é uma das estratégias de conservação dos anfíbios da região.

\section{Material e métodos}

\section{Área de estudo}

As amostragens de anuros foram realizadas em duas áreas inseridas no Bioma Mata Atlântica, sendo um dos pontos localizado no município de Santa Cruz do Sul e o outro no município de Venâncio Aires, ambos no Estado do Rio Grande do Sul, Brasil.

O município de Santa Cruz do Sul encontra-se na mesorregião do Centro Oriental RioGrandense e na Microrregião de Santa Cruz do Sul (2943'04" S 522ㄴ'33" O), prevalecendo o clima subtropical úmido. Venâncio Aires localiza-se na Mesorregião do Centro Oriental RioGrandense e na Microrregião de Santa Cruz do Sul (2936'21" S 5211'31" O), estando entre o Vale do Rio Pardo e o Vale do Taquari, sendo caracterizado por um clima subtropical úmido.

O ponto de estudo em Venâncio Aires encontra-se na localidade de Linha Estrela, área esta onde predominam culturas de arroz, contrastando com áreas de banhados, compostas principalmente por gramíneas e gravatás, sendo também um local de fácil acesso, por onde 
passa o Arroio Taquari Mirim, o que torna boa parte do solo úmido. O ponto sofre com as atividades antrópicas, onde destacam-se: o plantio de arroz, abertura de estrada e depósito de resíduos sólidos.

O ponto de estudo em Santa Cruz do Sul está localizado dentro da Universidade de Santa Cruz do Sul - UNISC, onde predominam gramíneas. Próximo ao local encontra-se um campo de futebol que, durante as amostragens, encontrava-se parcialmente alagado, servindo como sítio de reprodução para os anuros. No mesmo local também podemos encontrar mata fechada, proveniente de um remanescente de Mata Atlântica

\section{Metodologia aplicada}

Foram feitas amostragens dos anfíbios a partir do método de procura visual ativa e procura em ambientes de reprodução nos pontos estudados. Foram escolhidos somente anfíbios da ordem Anura devido a sua maior riqueza de espécies no bioma estudado e a facilidade de encontrá-los no local.

Para a localização dos anfíbios, foram realizadas saídas a campo entre outubro de 2014 e abril de 2015, que ocorreram mensalmente. As procuras ativas foram feitas principalmente durante o horário da tardinha e à noite, percorrendo a área estudada com o auxilio de uma lanterna, sempre com o esforço amostral de 02 horas, percorrendo a área a pé entre duas pessoas. Foram vasculhados troncos caídos, rochas, buracos, vegetação, e os banhados, que caracterizavam a área de estudo, a fim de encontrar os indivíduos.

Todos os animais avistados foram fotografados, identificados e manuseados com cuidado para melhor visualizar alguma característica morfológica que possibilitasse sua identificação, como padrões de colorações, calosidades, entre outros. Para isso, foi solicitado um comprovante do SISBIO/RAN \#10261-3 na qual autoriza a coleta de material fúngico nos anuros. Assim que o animal era capturado, passava-se delicadamente um swab por todo seu corpo, no qual os possíveis fungos ficavam aderidos. Não foi necessária a coleta ou transporte desses animais para laboratório, sendo estes logo soltos após as fotografias.

O swab utilizado era o swab em tubo transporte com meio stuart, que possibilitava o transporte e armazenamento do material à laboratório. Após feita a coleta, o swab era então identificado e acondicionado em uma geladeira, para posteriormente ser levado ao laboratório.

\section{Análise em laboratório}

Todo o material foi acondicionado no laboratório de fungos do bloco 20 da UNISC, onde era aplicada a técnica de iscas para isolamento de fungos aquáticos, adaptada de Milanez (1989).

O swab, anteriormente utilizado no anfíbio, era semeado em uma placa de Petri de plástico contendo água destilada estéril e iscas para fungos zoospóricos, previamente esterilizadas, como escamas de serpente, ecdises de insetos, papel celofane e penas. As primeiras iscas usadas foram penas, papel celofane repicado e ecdises de insetos, como um teste inicial. Nas últimas amostras, complementou-se os meios de crescimento dos fungos com iscas compostas de epiderme de serpentes. As placas foram mantidas em temperatura ambiente e esperavam-se no mínimo quatro dias para o crescimento das estruturas de reprodução dos fungos. Todos os fungos foram identificados com o auxílio de microscópio óptico e chaves de identificação. 


\section{Taxonomia e identificação}

Os caracteres utilizados para identificação dos fungos baseavam-se nas características morfológicas das estruturas reprodutivas (oogônios, zoósporos e anterídios). Todos os fungos amostrados foram identificados com base em bibliografia especializada e atualizada, na qual utilizou-se a chave de Putzke e Putzke (2013), para fungos zoospóricos.

Os anuros foram identificados com base em características morfológicas, na qual utilizou-se a chave de identificação de Ziegler e Maneyro (2008), juntamente com a ajuda de especialistas no assunto.

\section{Resultados e discussões}

\section{Anura}

Foram encontradas 9 espécies de anuros, em um total de 24 indivíduos amostrados, e estes distribuídos em 3 famílias, conforme a Tab. 1.

Tabela 1 - Lista de anfíbios encontrados. SCS = Santa Cruz do Sul; VA = Venâncio Aires.

\begin{tabular}{ccc}
\hline Família & Espécie & Registro \\
\hline Leptodactilidae & Leptodactylus latrans & VA; SCS \\
& Leptodactylus chaquensis & VA \\
& Leptodactylus latinasus & SCS \\
& Physalaemus gracilis & SCS \\
& Physalaemus cuvieri & SCS \\
& Pseudopaludicola falcipes & VA \\
Hylidae & Hypsiboas pulchellus & VA \\
& Scinax sp. & SCS \\
& Dendropsophus sanborni
\end{tabular}

\section{Fungos encontrados nos anuros amostrados}

Foram encontrados 6 táxons de fungos, distribuídos em 3 famílias, ocorrendo nos anfíbios anuros amostrados, conforme pode ser observado na Tab. 2 .

Tabela 2 - Táxons de fungos encontrados. SCS = Santa Cruz do Sul; VA = Venâncio Aires.

\begin{tabular}{ccc}
\hline Família & Táxon & Registro \\
\hline Saprolegniaceae & Achlya sp. & VA; SCS \\
& Saprolegnia sp. & VA; SCS \\
Leptomitaceae & Leptomitus sp. & SCS \\
& Apodachlya sp. & SCS \\
Chytridiaceae & Batrachochytrium dendrobatidis & SCS \\
& Chytriodiomycota & VA \\
\hline
\end{tabular}


Santa Cruz do Sul apresentou 5 táxons de fungos ocorrendo nos anfíbios amostrados, enquanto que Venâncio Aires apresentou 3 táxons de fungos amostrados. No ponto em Venâncio Aires observou-se os gêneros Achlya, Saprolegnia e indivíduos do Filo Chytridiomycota, sem possibilidade de identificação. Para Santa Cruz do Sul, foram registrados indivíduos de Achlya sp., Saprolegnia sp., Apodachlya sp., Leptomitus sp., a espécie Batrachochytrium dendrobatidis e representantes do Filo Chytridiomycota.

O número total de espécies de anuros foi o mesmo nos dois pontos, tendo sido amostradas 5 espécies para cada ponto. No ponto de amostragem em Venâncio Aires observou-se a ocorrência de Dendropsochus sanborni, Leptodactylus latrans, Hypsiboas pulchellus, Leptodactylus chaquensis e Pseudopaludicola falcipes. Enquanto que em Santa Cruz do Sul foram amostrados indivíduos de Physalaemus gracilis, Physalaemus cuvieri, Leptodactylus latrans, Leptodactylus latinasus e Scinax sp.

Dos 24 indivíduos de anuros amostrados, 21 deles apresentaram fungos zoospóricos na epiderme, sendo os gêneros Achlya e Saprolegnia os mais frequentemente observados. Saprolegnia sp. foi o fungo de maior ocorrência, sendo observado em 16 indivíduos de anuros, seguido de Achlya sp., com 12 amostras positivas, conforme Fig. 1.

Figura 1 - Quantidade de anuros amostrados que apresentaram diferentes táxons de fungos.

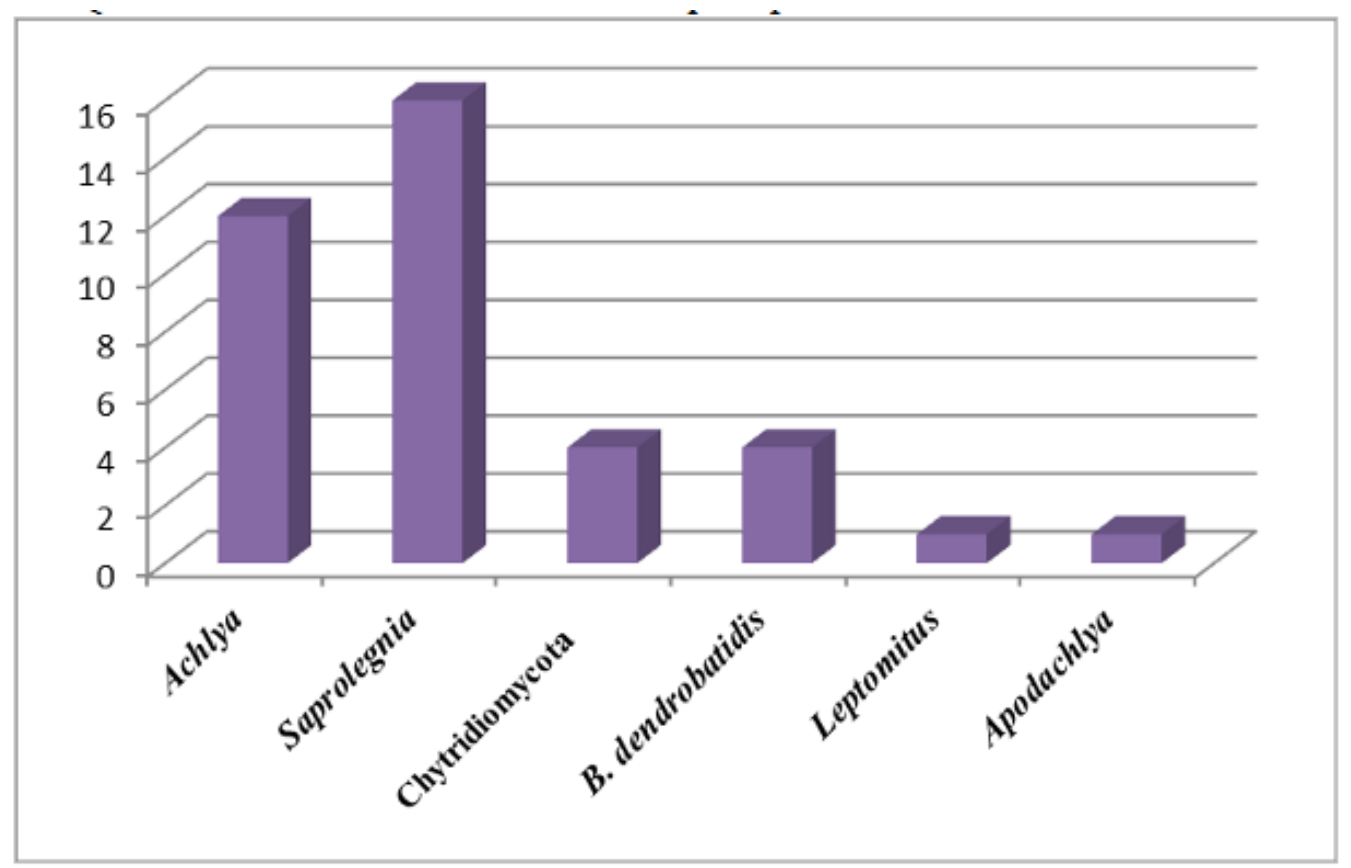

A saprolegniose e outras infeç̧ões por fungos aquáticos podem desenvolver-se em feridas ou úlceras bacterianas. A maioria das lesões é causada pelo gênero Saprolegnia, daí seu nome, saprolegniose, porém, esta doença inclui outro membro da família Saprolegniaceae, como o gênero Achlya, que também é considerado um patógeno de anfíbios e seus ovos (KUBITZA e KUBITZA, 1999).

Os Oomycetes são fungos cosmopolitas encontrados em ambientes aquáticos e terrestres, sendo a maioria saprófitas (PUTZKE e PUTZKE, 2013). Tão importante para os anfíbios, como a conservação do seu habitat, é necessária a existência de água para a sua reprodução e o desenvolvimento de sua fase aquática no seu ciclo de vida (BENÉITEZ, 2011). 0 fato de anuros necessitarem da água para sua reprodução e desenvolvimento condiz com as amostras positivas para Oomycetes, que são comumente encontrados em ambientes aquáticos. 
Em algumas amostras foi possível observar zoósporos ativos de Saprolegnia sp. Para melhor visualizar os zoósporos, principalmente a estrutura do flagelo, foi adicionada uma pequena gota de glucose de milho, na qual fazia os zoósporos nadarem mais lentamente, possibilitando observar os flagelos em movimento. Porém, na maioria das amostras, apenas observava-se oogônios e zoosporângios encistados cuja presença está relacionada à idade da cultura e o tipo de isca disponível em microclima.

Durante as análises dos fungos, observou-se zoósporos do fungo quítridio Batrachochytrium dendrobatidis em quatro amostras. Os quatro indivíduos que apresentaram o fungo, Leptodactylus latrans, Scinax sp., Physalaemus cuvieri e Leptodactylus latinasus, respectivamente, foram todas amostrados em um pequena vala alagada rodeada de gramíneas, por onde escoa um canal de esgoto, localizado dentro da UNISC em Santa Cruz do Sul.

Em parte das demais amostras, era possível observar os zoóporos e zoosporângios associados, tanto de quitrídios como de Oomycetes. Enquanto em outras apenas via-se os zoósporos encistados e zoosporângios já descarregados ou não, podendo observar-se ocasionalmente oogônios de representantes do filo Oomycota. Esta observação está de acordo com o estudo de Johnson \& Spare (2003), onde afirma-se que a duração de sobrevida de Batrachochytrium dendrobatidis em água varia de acordo com a fonte de água e da estirpe do fungo. Ainda, de acordo com o estudo, os zoósporos de $B$. dendrobatidis são altamente ativos quando colocados tanto em água deionizada, clorada ou água proveniente de um lago. $O$ ciclo do fungo continua até que ocorra uma inibição de crescimento, como a limitação de nutrientes ou pelo acúmulo de resíduos metabólicos. Isto confirma que a ausência da atividade de zoósporos, ou o crescimento de novos zoosporângios não é um indicador de uma cultura não viável ou morta.

O B. dendrobatidis é um fungo zoospórico, pertencente a um grupo de fungos conhecidos como quitrídios. Vivem em ambientes aquáticos, como lagos, cursos d'água, e solo úmido, (BERGER et al., 1999; BERGER et al., 2005; PIOTROWSKI et al., 2004; DASZAK et al., 1999), justamente onde encontravam-se os indivíduos de anuros que apresentaram este fungo.

B. dendrobatidis pode sobreviver em água corrente e deionizada por três a quatro semanas, enquanto que em água de lagos, os zoósporos mantêm viabilidade por períodos muito mais longos, provavelmente devido a um maior nível de nutrientes e substratos orgânicos (JOHNSON \& SPARE, 2003).

Dos 24 indivíduos amostrados, apenas 3 tiveram resultados negativos para fungos aquáticos (um indivíduo de Leptodactylus latras, um Physalaemus gracilis e um Pseudopaludicola falcipes).

No decorrer do trabalho, as primeiras iscas usadas foram penas, papel celofane repicado e ecdises de insetos, como um teste inicial. Nas últimas amostras, complementou-se os meios de crescimento dos fungos com iscas compostas de epiderme de serpentes. Nestes tipos de iscas, observou-se, então, o crescimento de fungos patógenos de anfíbios, como $\circ B$. dendrobatidis. Isto explica a ocorrência de $B$. dendrobatidis apenas nas últimas amostras.

Até então, este fungo quitrídio ainda não havia sido relatado para a região do Vale do Rio Pardo e Taquari no Rio Grande do Sul associado com anfíbios anuros, sendo este o primeiro registro de ocorrência da espécie no local.

A perda potencial de espécies de anfíbios representa uma das maiores ameaças a biodiversidade de vertebrados já registrada na história. Embora a perda de habitat seja a culpada pelo declínio de anfíbios, muitas espécies continuam a morrem em ambientes não perturbados (LAWRENCE, 2008). Muitos pesquisadores então se questionam se a infecção pelo $B$. dendrobatidis não teria alguma relação com a morte de anfíbios em habitats intocados. Sabe-se que a quitridiomicose está envolvida no desaparecimento de muitas populações regionais de anfíbios e que tem impulsionado algumas espécies endêmicas a extinção (COLLINS e STORFER, 2003). 
Em anuros, as espécies aquáticas estão mais associadas à quitridiomicose do que em espécies terrestres (PEARL et al., 2007). Segundo Kriger \& Hero (2007), os zoósporos de $B$. dendrobatidis raramente nadam mais que $2 \mathrm{~cm}$ antes de se encistar e, assim, a sua distribuição é muito facilitada em corpos d'água. Estas informações coincidem com as amostras de indivíduos que apresentaram $B$. dendrobatidis positivo. Estes 4 indíviduos (L. latrans, Scinax sp., $P$. cuvieri e $L$. latinasus) foram amostrados dentro de um corpo d'água ou muito próximos do mesmo, o que poderia facilitar a dispersão do fungo aquático.

Não houve registro de $B$. dendrobatidis no local de estudo em Linha Estrela, em Venâncio Aires. Uma possível hipótese para o quitrídio ocorrer somente no local de estudo em Santa Cruz do Sul pode estar associada ao escoamento de esgoto que se observa no local de amostragem. Foram encontrados diversos anfíbios usando este corpo d'água por onde sai o esgoto como sítio de reprodução, onde observou-se, inclusive, muitos girinos e ninhos de espuma. Para Gomes (2006), anfíbios podem desenvolver a quitridiomicose quando deparados a fatores debilitantes, como o aumento da poluição, perda de habitat ou outras alterações ambientais.

A maioria dos fungos amostrados foram identificados até nível de gênero, devido à dificuldade na identificação destas espécies por meio de características morfológicas. Isto sugere que muitas destas espécies ainda sejam desconhecidas da ciência, o que enfatiza a importância do estudo de fungos zoospóricos para melhor entendermos sua biologia e sua relação com o hospedeiro.

\section{Referências}

1. BENÉITEZ, M. J. F. Infecciones por Oomycetes em Problaciones de Anfibios de La Sierra de Gredos (Ávila). Efecto de La Radiación UV-B. 2011. 227 p. Tese de Doutorado (Departamento de Biología Animal, Parasitología, Ecología, Edafología y Química Agrícola)-Universidad de Salamanca, Salamanca, 2011.

2. BERGER, L.; MARANTELLI, G.; SKERRAT, L. F.; SPEARE, R. Virulence of the amphibian chytrid fungus Batrachochytrium dendrobatidis varies with the strain. Diseases of Aquatic Organims, v. 65, p. 181-186, 2005.

3. BERGER, L.; SPEARE, R.; HYATT, A. Diagnosis of chytriomycosis of amhibians by histological examination. Zoos Print Journal, v. 15, p. 184-190, 1999.

4. BERNARDE, P. S. Anfíbios e Répteis: Introdução ao Estudo da Herpetofauna Brasileira. Curitiba: Anolisbooks, 2012. 318 p.

5. BORGES-MARTINS, M.; COLOMBO, P.; ZANK, C.; BECKER, G. F.; MELO, M. T. Q. Biodiversidade das regiões da Lagoa do Casamento e dos Butizais de Tapes, Planície Costeira do Rio Grande do Sul. In: BECKER, F. G. et al. de (Org.). Anfíbios. Brasília: Ministério do Meio Ambiente, 2007. p. 276-291.

6. COLLINS. J. P.; STORFER, A. Global amphibian declines: sorting the hypotheses. Diversity and Distribuitions, v. 9, p. 89-98, 2003.

7. COLOMBO, P.; ZANK, C. Biodiversidade dos Campos de Cima da Serra. In: BOUNDBUCKUP, G. (Org.). 1. ed. Porto Alegre: Libretos, 2008. p. 104-111.

8. DASZAK, P.; BERGER, L.; CUNNINGHAM, A. A.; HYATT, A. D.; GREEN, D. E.; SPEARE, R. Emerging infectious diseases and amphibian population declines. Emerg Infect Dis, n. 5, p. 735-748, 1999. 
9. GOMES, A. L. Diversidade de Oomycota da Reserva Biológica de Paranapiacaba, Santo André, SP. 2006. 118 p. Dissertação de Mestrado (Instituto de Botânica da Secretaria do Meio Ambiente) - São Paulo, 2006.

10. JOHNSON, M. L.; SPEARE, R. Survival of Batrachochytrium dendrobatidis in water: quarantine and disease control implications. Emerg Infect Dis., 2003.

11. KRIGER, K. M.; HERO, J. M. Large-scale seasonal variation in the prevalence and severity of chytridiomycosis. Journal of Zoology, v. 271, p. 352-359, 2007.

12. KUBITZA, F.; KUBITZA, L. M. M. Tilápias: manejo nutricional e alimentar. Panorama da Aquicultura, v. 10, p. 31-53, 1999.

13. LAWRENCE, D. Batrachochytrium dendrobatidis: Chytrid disease. Aquatic Invasion Ecology, 2008.

14. PEARL, C. A.; BULL, E. L.; GREEN, D. E.; BOWERMAN, J.; ADAMS, M. J.; HYATT, A.; WENTE, W. H. Ocurrence of the amphibian pathogen Batrachochytrium dendrobatidis in the Pacific Northwest. J Herpetol., v, 41, p. 145-149, 2007.

15. PIOTROWSKI, J. S.; ANNIS, S. L.; LONGCORE, J. F. Physiology of Batrachochytrium dendrobatidis, a chytrid pathogen of amphibians. Mycologia, v. 96, 9-15, 2004.

16. PUTZKE, J.; PUTZKE, M. T. L. Os Reinos dos Fungos. 3. ed. Santa Cruz do Sul: EDUNISC, 2013.

17. ZIEGLER, L.; MANEYRO, R. Clave para la identificación de los Anfibios de Uruguay (Chordata: Amphibia). Universidad de la Republica - Facultad de Ciencias, Montevideo, 2008. 